\title{
The current distribution and status of leopards Panthera pardus in China
}

\author{
Alice Laguardia, Jan F. Kamler, Sheng Li, Chengcheng Zhang \\ ZHEFENG ZHOU and Kun SHI
}

\begin{abstract}
The leopard Panthera pardus, categorized globally as Near Threatened on the IUCN Red List, has the widest distribution of any wild felid species, although in Asia it has declined dramatically and five subspecies are Endangered or Critically Endangered. In China at least three subspecies have been reported to occur throughout much of the country, and in 1998 the population was estimated to be 1,00o. However, recent studies have indicated that leopards have disappeared from large areas, probably as a result of habitat loss, a low prey base and poaching, indicating this species may not be as common in China as previously believed. To examine this we reviewed recent literature and interviewed specialists to determine the current status and distribution of the leopard in China. Our findings indicate that the species has declined dramatically, with confirmation of presence at only 44 sites in 11 provinces, despite extensive surveys. Current populations are small and fragmented, and occur mainly in isolated nature reserves. We estimate a total population of only $174-348$ $P$. pardus japonensis (the north Chinese leopard), which is endemic to China, and $<_{30}$ individuals for each of the other subspecies whose distributions extend beyond China. We recommend that a separate IUCN assessment be made for $P$. pardus japonensis, and that this subspecies be categorized as Critically Endangered. Our findings are the first reliable estimates of the current distribution and status of the leopard in China, and provide valuable information that will help guide conservation efforts.
\end{abstract}

Keywords Amur leopard, China, conservation, Indochinese leopard, north Chinese leopard, Panthera pardus, Red List status

To view supplementary material for this article, please visit http://dx.doi.org/10.1017/So030605315000988

\footnotetext{
Alice Laguardia, Chengcheng Zhang and Kun Shi (Corresponding author) The Wildlife Institute, Beijing Forestry University, Tsinghua-east Rd 35, Beijing 100083, China. E-mail kunshi@bjfu.edu.cn

JAN F. KAMLER Wildlife Conservation Research Unit, Department of Zoology, The Recanati-Kaplan Centre, University of Oxford, Abingdon, UK; Panthera, New York, USA

SHeNG Li School of Life Sciences, Peking University, Beijing, China

Zhefeng ZHou Wocheng Institute of Ecology and Environment, Taiyuan, Shanxi, China

Received 25 April 2015. Revision requested 24 June 2015.

Accepted 27 July 2015. First published online 30 October 2015.
}

\section{Introduction}

The leopard Panthera pardus has the widest 1 distribution of any wild felid species, ranging from western and southern Africa to the Russian Far East and Java (Stein \& Hayssen, 2013). This is largely a result of the species' high adaptability, as it can occupy diverse ecosystems ranging from tropical rainforests to boreal forests and arid savannahs (Bertram, 1999) and take a large variety of prey species (Hayward et al., 2006). Despite these characteristics, the leopard has declined dramatically worldwide (Stein \& Hayssen, 2013), and disappeared from at least one-third of its historical range in Africa (Ray et al., 2005). In Asia, leopards have exhibited dramatic declines in the Middle East (Khorozyan, 2008; Mallon et al., 2008), Russian Far East (Jackson \& Nowell, 2008), Sri Lanka (Kittle \& Watson, 2008) and Java (Ario et al., 2008), and consequently subspecies occupying these regions are categorized as Endangered or Critically Endangered on the IUCN Red List. Although the leopard still occupies much of its historical distribution in India (Karanth et al., 2010), the species' status is unknown across large regions of Asia, particularly in China where data on leopards are outdated and limited.

Historically, the leopard was distributed throughout China, with the exception of the arid Gobi desert and mountainous western regions at elevations $>4,000 \mathrm{~m}$. At present the species reportedly occurs in at least 19 provinces (Bao et al., 2010) and is on the list of fauna for many protected areas. Despite these optimistic reports, there are few recent records in most of these areas (Li et al., 2010; Jutzeler et al., 2010). Comparisons of several recent leopard surveys with a nationwide mammal assessment carried out during 19952000 concluded that most of the existing habitat is no longer suitable and local extinctions have occurred in several regions across the leopard's range (Ran \& Chen, 2002; Liu et al., 2007a,b, 2009). Therefore it is highly unlikely that the only available estimate of the leopard population in China (1,00o; Ma, 1998) is still reliable.

Lack of information on the current distribution and population of a species can undermine conservation efforts, as such information is essential for developing appropriate strategies to maintain viable populations. The aim of our study therefore was to conduct a review of records of the leopard in China from 2000 onwards, to determine the species' current status and distribution and to make recommendations for its conservation. 


\section{Subspecies dilemma}

According to phylogenetic classifications (Miththapala et al., 1996; Uphyrkina et al., 2001) there are at least three, and probably four, subspecies of leopard in China but their geographical boundaries are unclear. The Amur leopard $P$. pardus orientalis occupies the north-east, as far south as the area north of Beijing. The Indochinese leopard $P$. pardus delacouri occurs in the south-east, presumably including all of Yunnan Province and as far north as the Pearl River (Zhu Jiang in Chinese) in Guangxi and Guangdong provinces (Miththapala et al., 1996). The most widespread subspecies in China is the north Chinese leopard P. pardus japonensis, commonly referred to as $P$. pardus fontanierii in the Chinese literature. This subspecies is endemic to China and occurs in the central and eastern regions, presumably as far north as the Beijing area, and as far south as the Pearl River, including Sichuan and Guizhou provinces. The subspecific status of leopards in Xizang (Tibet) Autonomous Region (hereafter, Tibet) is uncertain. Although this population could be P. pardus fusca (Miththapala et al., 1996; Uphyrkina et al., 2001), this subspecies has been considered synonymous with $P$. pardus delacouri in southern China (Smith \& Xie, 2008). However, the Tibet population is separated from the main distribution of $P$. pardus delacouri by high mountain ranges, although the Tibet population occupies similar habitat and shares a continuous distribution with $P$. pardus japonensis. Genetic research is necessary to clarify the subspecies of the Tibet population; here, we consider it to be $P$. pardus japonensis. Leopards from southcentral Tibet, however, such as those near Mount Everest, are almost certainly $P$. pardus fusca.

\section{Current distribution}

Searches were conducted for newspaper articles, scientific reports and peer-reviewed publications, in English or Chinese, published from 2000 onwards, which contained records of the leopard in China. We searched Google Scholar (2015) for the terms 'panthera pardus AND china OR japonensis OR delacouri OR orientalis OR fusca' for 2000-2015, resulting in c. 3,230 items. As this database does not include all Chinese journals we also searched the China National Knowledge Internet (2015) with the keyword 'jinqianbao' ('leopard' in Chinese) for 2000-2015, resulting in 1,736 items. The titles of items, then the abstracts and finally the full articles were filtered by relevance to our search objectives, reducing the number of items considerably. The corresponding authors of key publications and key felid experts were contacted for additional information. A final total of 28 publications were used (Supplementary Table $\mathrm{S}_{1}$ ) and seven experts provided additional information as personal communications or unpublished data. Identification of species records from sightings, scats and signs is subject to bias (Farrell et al., 2000; Davison et al., 2002; Prugh \& Ritland, 2005; Harrington et al., 2009; Laguardia et al., 2015) and therefore extreme caution was adopted when categorizing records (e.g. consideration of the experience of the person making the observation, presence of sympatric carnivores).

The results confirmed the presence of the leopard in 11 provinces (Fig. 1; Supplementary Table S1), in a total of 44 locations where the species has been detected using camera traps, carcasses of poached individuals were recovered, or sightings or scat identifications were made by experienced researchers. Thirty-three of the records were in nature reserves or county forests and 11 in unprotected sites (Supplementary Table $\mathrm{S}_{1}$ ). An additional six provinces had potential (Fig. 1; Supplementary Table $\mathrm{S}_{1}$ ) areas of leopard occurrence, based on interviews with local staff, questionnaires to resident communities, livestock depredation reports or habitat quality assessments. In 27 locations the leopard was considered absent (Supplementary Table S1) because no signs were found, although there has been insufficient survey effort in some parts of the historical distribution. Although most camera-trap surveys occurred within protected areas, this is unlikely to bias our results because remaining forest habitat and potential prey species are primarily restricted to these areas.

We summarize the records (details in Supplementary Table S1) and distributions for each subspecies (Fig. 1):

\section{Amur leopard P. pardus orientalis}

In Jilin and Heilongjiang provinces leopards were probably extirpated by the 1990 os (Jutzeler et al., 2010) but recent efforts to create large nature reserves along the ChineseRussian border have made it possible for individuals to cross into China. Camera traps have recorded leopards in several areas of Jilin Province (Huang et al., 2012; Xiao et al., 2014a; Beijing Normal University, 2015), and recent sign surveys and camera traps have recorded leopards in south-eastern Heilongjiang Province (Jutzeler et al., 2010; Beijing Normal University, 2015).

\section{North Chinese leopard P. pardus japonensis}

In eastern and central China leopard populations are greatly reduced and highly fragmented. Recent camera-trap surveys and other evidence confirmed the presence of the subspecies in only eight provinces (from north to south): northern Hebei, Shanxi, Shaanxi, Ningxia, northern Henan, western Sichuan, southern Qinghai, and Tibet. Most populations in these provinces are small, and occur in isolated protected areas, and it is unknown whether these subpopulations are viable in the long term. Although some records were from outside protected areas, it is probable that these subpopulations 


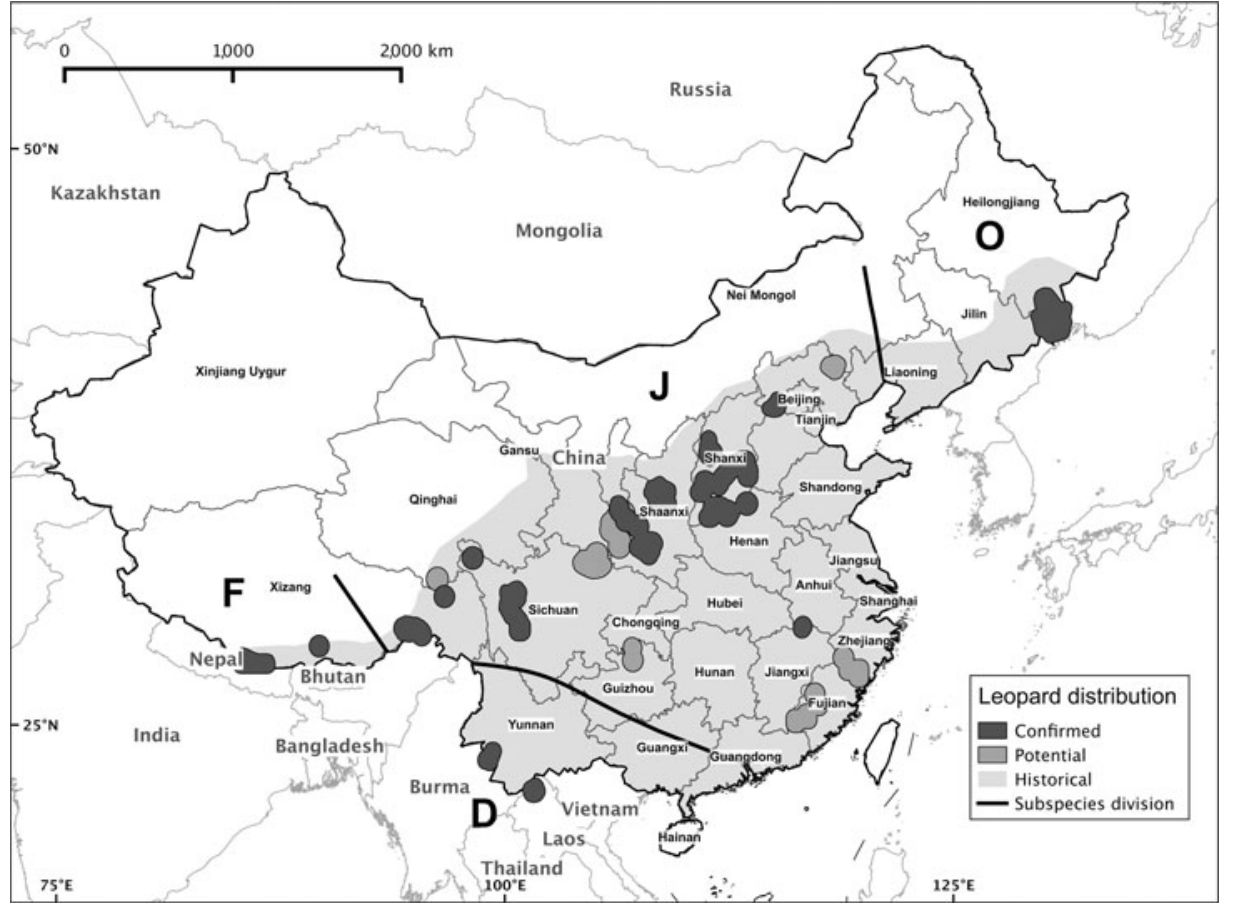

FIg. 1 The current distribution of subspecies of the leopard Panthera pardus in China: $\mathrm{O}$, $P$. pardus orientalis; J, P. pardus japonensis; D, P. pardus delacouri; F, $P$. pardus fusca. function as sinks as a result of the higher human disturbance and lower prey numbers, similar to the situation reported for tigers Panthera tigris in India and Nepal (Karanth et al., 2013).

In Hebei Province camera traps recorded leopards in 2013 and $2014,<150 \mathrm{~km}$ from Beijing (T. Song, unpubl. data); the status in other regions of the province is unknown but numbers are likely to be low. Most records were attributed to Shanxi Province, where extensive camera trapping during 2007-2014 identified leopard populations in 16 protected areas across the province (Sohu News, 2003; Song et al., 2014; Sina News, 2015; Xinhuanet News, 2015; Z. Zhou, unpubl. data). In the neighbouring Shaanxi Province there were leopard records from six nature reserves in addition to two verified attacks on people and two leopards killed by poachers (Sohu News, 2003, 2006; Li et al., 2010; Wu et al., 2012; Liu et al., 2013; Xinhuanet News, 2014; S. Li, pers. comm.). In Ningxia Autonomous Region there were 25 recent records of leopards (Gao et al., 2007; CCTV, 2015; China Economic Net, 2015). Leopards also occur in the northern part of Henan Province, where eight leopards were killed during 1999-2007, in addition to multiple sightings and reports of livestock predation by leopards (Wang et al., 2008). Habitat restoration efforts have increased the prey base (mostly hare Lepus sp. and wild boar Sus scrofa) and could have had a positive effect on the leopard population in this area (Wang et al., 2008; Hou, 2012).

In Sichuan Province the current status of leopards is unclear, and all recent records are from the west, including camera trap images and fresh scats. Intensive camera trapping is underway ( $\mathrm{S}$. Li, pers. comm.) to identify the subspecies' current distribution in the province. During the 1970 s and 1980s leopards were recorded in Wolong Nature Reserve (Schaller et al., 1985; Johnson et al., 1993), one of the largest protected areas in Sichuan, where intensive research on giant pandas Ailuropoda melanoleuca has taken place. However, multiple camera trapping studies during 2005-2009 did not record leopards (Li et al., 2010) and they are probably extirpated from the reserve. Cameratrapping studies in an additional nine protected areas in central Sichuan during 2002-2009 also failed to record leopards, even though they were on the official mammal lists of the reserves, indicating this species might be extirpated from large areas of the province (Li et al., 2010; Xiao et al., 2014b). In Tibet leopards were recently recorded in the east (S. Li, pers. comm.). There are also several recent records of leopards from south-central Tibet (Hu et al., 2014), including the forest zone of Mt Everest (Hou, 2012). The records from south-central Tibet are probably subpopulations of $P$. pardus fusca, however. In Qinghai Province, data from local interviews suggested leopards occur in the south (D. Wang, pers. comm.).

There are no recent confirmed records from the other provinces in central or eastern China. In Gansu Province Liu et al. (2007a) did not find any leopard sign during an 80-day field survey in key areas during December 2003March 2004. However, 26 unconfirmed leopard occurrences (reports of leopard tracks and leopard attacks on livestock) were recorded in the last 5 years. The leopard may be extirpated from most of its former range in Gansu and its potential distribution limited to areas on the border with Shaanxi and Sichuan. Leopard tracks were reported in 2006 in southcentral Inner Mongolia but there are no other records despite 
camera traps having been used extensively in this province for studies of Eurasian lynx Lynx lynx and other carnivores.

Leopards appear to have been extirpated throughout all other provinces in central and eastern China, including Hunan, Hubei, Zhejiang, Fujian, Guangxi and Jiangxi. In Jiangxi Province one leopard was recorded by a security camera in 2003 or 2004 (S. Li, pers. comm.) but afterwards no further leopards were recorded there despite extensive camera trapping and therefore this population is probably now extirpated (Tilson et al., 2004). Recent camera trapping surveys did not detect leopards in Hunan (Tilson et al., 2004; Dahmer et al., 2014; Liu et al., 2014) or Guangxi (Wang et al., 2014). Based on records of livestock losses, interviews with witnesses and habitat quality, some researchers have suggested that potential leopard populations existed in nature reserves in Zhejiang, Fujian and Guizhou provinces (Ran \& Chen, 2002; Liu et al., 2007b; Liu et al., 2009). However, recent camera trapping in several nature reserves in these provinces failed to detect leopards (Tilson et al., 2004; D. Song, pers. comm.) and the species is probably extirpated from these provinces.

\section{Indochinese leopard P. pardus delacouri}

In the south-east this subspecies has recently been recorded in camera traps in two nature reserves in south-western Yunnan Province near the border with Myanmar (The Wildlife Institute, Beijing Forestry University, unpubl. data; Jutzeler et al., 2010) but the population is low (probably $<10$ individuals in each reserve) and is unlikely to recover because of the high levels of habitat fragmentation and poaching, and low prey numbers. There are no other recent records of $P$. pardus delacouri in south-eastern China and this subspecies might be on the verge of extirpation in the country. The distribution and status of this subspecies is currently being assessed in the remaining countries of its distribution (J.F. Kamler, unpubl. data).

\section{Population status and major threats}

The previous nationwide estimate of 1,00o leopards ( $\mathrm{Ma}$, 1998) is now outdated. The available information that exists is limited to specific areas or nature reserves. Particular effort has been dedicated to surveying for $P$. pardus orientalis in north-eastern China, using both camera traps and sign surveys, and initial results have suggested a population of 20-25 (Huang et al., 2012; Xiao et al., 2014a; Jilin Forestry Department, WCS, \& WWF, unpubl. data). Additionally, 42 individual Amur leopards were identified during 20122014 (Beijing Normal University, 2015; Wang et al., 2015), although many of these might be cross-border individuals and not resident leopards. The total number of $P$. pardus delacouri in south-eastern China is probably $<20$. Similarly, the number of presumed $P$. pardus fusca in south-central Tibet is probably small, also with $<20$ individuals.

There are an estimated 60 P. pardus japonensis in Henan Province (Wang et al., 2008; Hou., 2012), 20-30 in southern Ningxia (Gao et al., 2007), 5-10 in southern Shanxi (Z. Zhou, unpubl. data), 14 in a county forest in northern Shanxi (Song et al., 2014), 12 in Fujian (Liu et al., 2009), 121 in Guizhou (Ran \& Chen, 2002) and $<10$ in Zhejiang (Liu et al., 2009). There are no estimates available for any of the other provinces or nature reserves. The information collected from articles, reports and personal communications is not sufficient to provide a population estimate for $P$. pardus japonensis. Therefore, we estimated a population size range for this subspecies based on the number of confirmed leopard locations ( 33 sites), the mean area of the sites $\left(255 \mathrm{~km}^{2}\right)$ and densities of 1 and 2 leopard per $100 \mathrm{~km}^{2}$. We chose 1 leopard per $100 \mathrm{~km}^{2}$ as a minimum density because that was the estimated leopard density in a 2014 study of leopards in Lishan Nature Reserve in southern Shanxi Province (A. Laguardia, unpubl. data.) and the density reported for leopards in Bhutan (Wang \& Macdonald, 2009) in similar forested mountain habitat. We chose 2 per $100 \mathrm{~km}^{2}$ as a maximum density to account for the possibility of higher leopard densities in some areas with more favourable habitat and prey numbers. Leopard densities are unlikely to be $>2$ per $100 \mathrm{~km}^{2}$ anywhere in China. Our estimates gave a total population of 92-183 for confirmed areas. If we also include potential leopard locations (19 sites, mean area $=433 \mathrm{~km}^{2}$ ) then the total population estimate is $174-348$.

The reasons for the decline of leopard populations and their disappearance from many areas in China have yet to be investigated. Leopards are known to be successful at adapting to altered habitat and can persist as long as there is an adequate prey base, but they cannot withstand intense persecution. Retaliatory killings as a result of human-wildlife conflicts and poaching for the wildlife trade are reported in several provinces (Gao et al., 2007, Liu et al., 2007a, Wang et al., 2008, Xinhuanet News, 2014). In addition, low prey numbers, especially of wild ungulates, are reported even in many nature reserves. Loss and fragmentation of habitat through logging, farming, mining, expanding settlements and road construction are also consistently described as the main threats. Consequently, leopard subpopulations are now more vulnerable because they are small and isolated, with unsuitable habitat between them.

\section{Conservation actions}

Panthera pardus is categorized as Near Threatened on the IUCN Red List (Henschel et al., 2008), although five subspecies, all from Asia, are categorized as Endangered or Critically Endangered. For China assessment of intraspecific taxa is available only for $P$. pardus orientalis, which is categorized as Critically Endangered (Jackson \& Nowell, 2008). 
As a result of the immediate risk of extinction highlighted by our review, we recommend that $P$. pardus japonensis should have a separate subspecies assessment. With its recent and dramatic range reduction in China, an estimated population of 174-348, and with no subpopulation $>50$ individuals, we recommend $P$. pardus japonensis is categorized as Critically Endangered based on criteria A2b,c and C2a(i) (IUCN, 2012). The China Species List has already categorized Panthera pardus as Critically Endangered and it is a Class I protected species and among 13 particularly important species targeted for conservation and restoration (Wang \& Xie, 2004; Lu et al., 2010).

Compared to other Panthera species, such as the snow leopard Panthera uncia and tiger, leopards receive little attention and limited funding (Jutzeler et al., 2010). The international conservation community in particular has not yet recognized the dramatic decline of this species (Stein \& Hayssen, 2013), especially in China. To ensure the long-term survival of leopards in China, information about their population dynamics and habitat requirements in relatively small isolated reserves is needed so that effective conservation action can be implemented.

Similar to other large carnivore species, leopards have large home ranges and naturally occur at relatively low densities, requiring large areas to persist. However, their persistence in China will probably be limited to nature reserves as a result of extensive habitat loss and low prey numbers outside these areas. Therefore, to avoid problems related to small and fragmented populations (e.g. inbreeding depression), habitat and leopard prey in nature reserves will need to be restored and expanded. To foster connection between nature reserves, corridors containing suitable habitat need to be established to allow movement and increase gene flow between otherwise isolated populations (Dutta et al., 2013). Priority should also be given to increasing patrols against poaching. Although it is has been illegal to kill leopards in China since 1988, poaching incidents are still reported, indicating that persecution of the species has yet to be eliminated. National surveys for wildlife are ongoing in China, and our findings, together with new data, will help prioritize conservation efforts and ensure appropriate measures are taken to secure the leopard in China.

\section{Acknowledgements}

We thank all the researchers that contributed valuable information on leopard occurrence in China, especially Weidong Bao (Beijing Forestry University), Eve Bohnett (Beijing Forestry University), Ying Chen (Beijing Forestry University), Pengju Chen (Beijing Forestry University), Limin Feng (Beijing Normal University), Yiming $\mathrm{Hu}$ (Chinese Academy of Sciences), Dazhao Song (Chinese Felid Conservation Alliance), Dajun Wang (Peking
University), Charlotte Whitham (Beijing Forestry University) and the staff of Wocheng Institute of Ecology and Environment.

\section{References}

Ario, A., Sunarto, S. \& Sanderson, J. (2008) Panthera pardus melas. In The IUCN Red List of Threatened Species v. 2015.2. Http:// www.iucnredlist.org [accessed 8 September 2015].

BaO, W., XU, J., Cui, G. \& Frisina, M.R. (2010) Cat research in China. Cat News, $\mathrm{S}_{5}, 7-9$.

Beijing Normal University (2015) Academic News: Monitoring and protection go hand in hand for decades, the Siberian tiger population returns to growth. Http://www.bnu.edu.cn/xzdt/77675. html [accessed 30 March 2015]. [In Chinese]

Bertram, B.C.B. (1999) Leopard. In The Encyclopedia of Mammals (ed. D.W. Macdonald), pp. 44-48. Andromeda Oxford Limited, Oxford, UK.

CCTV (2015) Guyuan, Ningxia: ran into leopard while on patrol, expert confirmed identification. Http://news.cntv.cn/2015/o1/28/ VIDE1422443522542276.shtml [accessed 5 February 2015]. [In Chinese]

China Economic Net (2015) Netizen photographed leopard again in Liupanshan. Http://www.ce.cn/celt/wyry/201502/o3/t20150203_ 4498727.shtml [accessed 5 March 2015]. [In Chinese]

China National Knowledge Internet (2015) Http://www.ckin. net [accessed 5 March 2015].

Dahmer, T.D., Gui, X. \& Tian, S. (2014) Camera-trapping for south China tiger in Hupingshan National Nature Reserve, Hunan Province, China. Chinese Journal of Wildlife, 35, 19-25.

Davison, A., Birks, J.D.S., Brookes, R.C., Braithwaite, T.C. \& Messenger, J.E. (2002) On the origin of faeces: morphological versus molecular methods for surveying rare carnivores from their scats. Journal of Zoology, 257, 141-143.

Dutta, T., Sharma, S., Maldonaldo, J.E., Wood, T.C., Panwar, H.S. \& Seidensticker, J. (2013) Gene flow and demographic history of leopards (Panthera pardus) in the central Indian highlands. Evolutionary Applications, 6, 949-959.

Farrell, L.E., Roman, J. \& Sunquist, M.E. (2000) Dietary separation of sympatric carnivores identified by molecular analysis of scats. Molecular Ecology, 9, 1583-1590.

GAo, E., Hu, D., WAnG, Z. \& BAI, Q. (2007) An investigation of leopard in Liupan Mountain Nature Reserve. Forest Resources Management, 1, 80-82. [In Chinese]

Google Scholar (2015) Http://scholar.google.com [accessed 5 March 2015].

Harrington, L.A., Harrington, A.L., Hughes, J., Stirling, D. \& Macdonald, D.W. (2009) The accuracy of scat identification in distribution surveys: American mink, Neovison vison, in the northern highlands of Scotland. European Journal of Wildlife Research, 56, 377-384.

Hayward, M.W., Henschel, P., O’Brien, J., Hofmeyr, M., Balme, G. \& Kerley, G.I.H. (2006) Prey preferences of the leopard (Panthera pardus). Journal of Zoology, 270, 298-313.

Henschel, P., Hunter, L., Breitenmoser, U., Purchase, N., Packer, C., Khorozyan, I. et al. (2008) Panthera pardus. In The IUCN Red List of Threatened Species v. 2015.2. Http://www. iucnredlist.org [accessed 8 September 2015].

Hou, D. (2012) Leopard found in Jiaozuo. Jiaozuo Yearbook, 230-240. [In Chinese]

Hu, Y., Yao, Z., Huang, Z., Tian, Y., Li, H., Pu, Q. et al. (2014) Mammalian fauna and its vertical changes in Mt Qomoloangma 
National Nature Reserve, China. Acta Theriologica Sinica, 34, 28-37. [In Chinese]

HuAng, C., MA, Y. \& Zhang, M. (2012) Study on protection countermeasures for Amur leopard. Chinese Journal of Wildlife, 33, 163-165. [In Chinese]

IUCN (2012) IUCN Red List Categories and Criteria: Version 3.1. 2nd edition. IUCN, Gland, Switzerland and Cambridge, UK.

Jackson, P. \& Nowell, K. (2008) Panthera pardus orientalis. In The IUCN Red List of Threatened Species v. 2015.2. Http://www. iucnredlist.org [accessed 8 September 2015].

Johnson, K.G., Wei, W., Reid, D.G. \& Jinchu, H. (1993) Food habits of Asiatic leopards (Panthera pardus fusea) in Wolong Reserve, Sichuan, China. Journal of Mammalogy, 74, 646-650.

Jutzeler, E., Wu, Z., Liu, W. \& Breitenmoser, U. (2010) Leopard Panthera pardus. Cat News, $\mathrm{S}_{5}, 30-33$.

Karanth, K.K., Nichols, J.D., Karanth, K.U., Hines, J.E. \& Christensen, Jr, N.L. (2010) The shrinking ark: patterns of large mammal extinctions in India. Proceedings of the Royal Society of London B, 277, 1971-1979.

Karanth, K.U., Gopalaswamy, A.M., Karanth, K.K., Goodrich, J., Seidensticker, J. \& Robinson, J.G. (2013) Sinks as saviors: why flawed inference cannot assist tiger recovery. Proceedings of the National Academy of Sciences of the United States of America, 110, e110.

Kittle, A. \& Watson, A. (2008) Panthera pardus kotiya. In The IUCN Red List of Threatened Species v. 2015.2. Http://www. iucnredlist.org [accessed 8 September 2015].

Khorozyan, I. (2008) Panthera pardus saxicolor. In The IUCN Red List of Threatened Species v. 2015.2. Http://www.iucnredlist.org [accessed 8 September 2015].

Laguardia, A., Wang, J., Shi, F.L., Shi, K. \& Riordan, P. (2015) Species identification refined by molecular scatology in a community of sympatric carnivores in Xinjiang, China. Zoological Research, 36, 72-78.

Li, S., WAnG, D., Lu, Z. \& McSheA, W.J. (2010) Cats living with panda. Cat News, 52, 20-23.

Liv, C., Zou, Q., Gao, E., Hua, C. \& Liv, W. (2009) The distribution of leopard Panthera pardus in Fujian province. Forestry Science \& Technology, 34, 35-37. [In Chinese]

Liv, F., Su, X., Li, D., WANG, B. \& Zhang, Z. (2014) Using camera traps to investigate animal diversity in Hunan Gaowangjie National Nature Reserve. Biodiversity Science, 22, 779-784. [In Chinese]

LiU, W., Hu, D. \& GAO, E. (2007a) Surviving status of leopard panthera pardus in Gansu province. Sichuan Journal of Zoology, 26, 86-88. [In Chinese]

LiU, W., GAO, E. \& Hu, D. (2007b) The distribution of leopard Panthera pardus in Zhejiang province. Special Wild Economic Animal and Plant Research, 3, 43-45. [In Chinese]

Liu, X., Wu, P., Songer, M., Cai, Q., He, X., Zhu, Y. \& Shao, X. (2013) Monitoring wildlife abundance and diversity with infra-red camera traps in Guanyinshan Nature Reserve of Shaanxi Province, China. Ecological Indicators, 33, 121-128.

Lu, J., Hu, D. \& YANG, L. (2010) Legal status and conservation of cat species in China. Cat News, $\mathrm{S}_{5}, 5-6$.

MA, Y.Q. (1998) Panthera pardus. In China Red Data Book of Endangered Animals: Mammalia (ed. S. Wang), pp. 116-118. Science Press, Beijing, China.

Mallon, D.P., Breitenmoser, U. \& Ahmad Khan, J. (2008) Panthera pardus nimr. In The IUCN Red List of Threatened Species v. 2015.2. Http://www.iucnredlist.org [accessed 8 September 2015].

Miththapala, S., Seidensticker, J. \& O’Brien, S.J. (1996) Phylogeographic subspecies recognition in leopards (Panthera pardus): molecular genetic variation. Conservation Biology, 10, 11151132.
Prugh, L.R. \& Ritland, C.E. (2005) Molecular testing of observer identification of carnivore feces in the field. Wildlife Society Bulletin, 33, 189-194.

RAN, J. \& Chen, H. (2002) The wild leopard and its protection in Guizhou province. Guizhou Forestry Science and Technology, 30, 2428. [In Chinese]

Ray, J.C., Hunter, L. \& Zigouris, J. (2005) Setting Conservation and Research Priorities for Larger African Carnivores. Working Paper No. 24. Wildlife Conservation Society, New York, USA.

Schaller, G.B., Jinchu, H., Wenshi, P. \& Jing, Z. (1985) The Giant Pandas of Wolong. The University of Chicago Press, Chicago, USA.

Sina NEWs (2015) Leopard photographed for the first time in Sixiannao Nature Reserve, Shanxi, in the boundaries of Yushe, Taigu and Qi counties. Http://shanxi.sina.com.cn/news/fazhi/2015-03-23/ detail-iawzuney0986723.shtml [accessed 30 March 2015]. [In Chinese]

Sohu News (2003) Leopard confronted people for five hours and captured in Fengxiang county, Shaanxi, thousands of onlookers saw it. Http://news.sohu.com/70/82/news205928270.shtml [accessed 5 March 2015]. [In Chinese]

Soнu News (2006) Wild leopard trespassed into people's home in Shaanxi. Http://news.sohu.com/20060304/n242121450.shtml [accessed 5 March 2015]. [In Chinese]

Song, D., Wang, B., Jiang, J., Wan, S., Cui, S., Wang, T. \& Feng, L. (2014) Using camera trap to monitor a north Chinese leopard (Panthera pardus japonensis) population and their main ungulate prey. Biodiversity Science, 22, 733-736. [In Chinese]

Smith, A.T. \& Xie, Y. (2008) A Guide to the Mammals of China. Princeton University Press, New Jersey, USA.

Stein, A.B. \& Hayssen, V. (2013) Panthera pardus (Carnivora: Felidae). Mammalian Species, 47, 30-48.

Tilson, R., Defu, H., Muntifering, J., \& Nyhus, P. J. (2004) Dramatic decline of wild South China tigers Panthera tigris amoyensis: field survey of priority tiger reserves. Oryx, 38, 40-47.

Uphyrkina, O., Johnson, W.E., Quigley, H., Miquelle, D., Marker, L., Bush, M. \& O’Brien, S.J. (2001) Phylogenetics, genome diversity and origin of modern leopard, Panthera pardus. Molecular Ecology, 10, 2617-2633.

WAng, S. \& XIE, Y. (2004) China Species Red List. Volume I. Higher Education Press, Beijing, China.

WANG, G., ShI, Z., LiU, X., ZhoU, Q. \& XIAO, Z. (2014) Camera-trap survey of mammals and birds in Huaping National Nature Reserve, Guangxi. Biodiversity Science, 22, 785-787. [In Chinese]

WANG, H., LU, J., TANG, F., LIU, J. \& KonG, J. (2008) Resources status and protection of Panthera pardus in Taihangshan Mountain National Reserve, Jiyuan, China. Journal of Henan Forestry Science and Technology, 28, 94-95. [In Chinese]

WANG, S.W. \& MACDONALD, D.W. (2009) The use of camera traps for estimating tiger and leopard populations in the high altitude mountains of Bhutan. Biological Conservation, 142, 606-613.

Wang, T., Feng, L., Mou, P., Wu, J., Smith, J.L., XiAo, W. et al. (2015) Amur tigers and leopards returning to China: direct evidence and a landscape conservation plan. Landscape Ecology, in press, http://dx.doi.org/10.1007/s10980-015-0278-1.

Wu, P., Liu, X., Cai, Q., He, X., Songer, M., Zhu, Y. \& Shao, X. (2012) The application of infrared camera in mammal research in Guanyinshan Nature Reserve, Shaanxi. Acta Theriologica Sinica, 32, 67-71. [In Chinese]

Xiao, W., Feng, L., Zhao, X., Yang, H., Dou, H., Cheng, Y. et al. (2014a) Distribution and abundance of Amur tiger, Amur leopard and their ungulate prey in Hunchun National Nature Reserve, Jilin. Biodiversity Science, 22, 717-724. [In Chinese]

XiaO, Z., Hu, L., WANG, X., ShanG, T., Zhu, D., Zhao, Z. \& HuAnG, X. (2014b) Wildlife diversity after Wenchuan Earthquake: a case from 
Guangguangshan Valley of Longxi-Hongkou National Nature Reserve, south-west China. Biodiversity Science, 22, 794-797. [In Chinese]

Xinhuanet News (2014) Another rare leopard killed in China. Http:// news.xinhuanet.com/english/china/2014-01/24/c_133071323.htm [accessed 24 October 2014].

Xinhuanet News (2015) Leopard was photographed for the first time in Pangquangou National Nature Reserve. Http://www.sx.xinhuanet. com/newscenter/2015-03/21/c_1114715864.htm [accessed 30 March 2015]. [In Chinese]

\section{Biographical sketches}

Alice Laguardia's research interests include the conservation of fragmented populations, non-invasive genetic techniques and species distribution modelling. JAN F. KAMLER is interested in the conservation of large carnivores and their prey. He is especially interested in how large carnivores affect the ecology of smaller carnivores and their prey, and what effects this has on ecosystems. SHENG LI is a wildlife researcher working on the ecology and conservation of large forest mammals, especially carnivores and ungulates, in south-western China. ChengCheng ZHANG is interested in using genetic methods for a deeper understanding of carnivores and their conservation. ZHEFENG $\mathrm{ZHOU}$ is founder of the Wocheng Institute for Ecology and Environment, focusing on biodiversity monitoring and conservation in Shanxi province. KUN SHI, as Secretary-general of the China Cats Specialist Group, is leading a feline research group at the Wildlife Institute of Beijing Forestry University, focusing on conservation of the snow leopard, leopard and tiger. 